\title{
GRADING PROCESS ENGINEERING WITHIN TILAPIA (Oreochromis niloticus) FISH PONDS
}

\section{Said Elshahat Abdallah* Wael Mohamed Elmessery**}

\begin{abstract}
\end{abstract}
Despite the emergence trend of trying to mechanize all agricultural operations in Egyptian fields several decades ago. But that aquaculture still does not have any significant share in this direction through nursing, rearing, harvesting and even postharvest techniques. Tilapias grading is considered to be one of the most important postharvest processes for marketing optimization. The main idea of manufacturing Tilapias grader is depend on the basics of fish behavior (attractive to current water (rheotactic)) by stimulating the Tilapias to trace the withdrawn water within the grader passed or retained through four sieves which have been placed in Tilapias movement course doing self-grading. Sieves sizes were determined according to preliminary study of Tilapias morphology. The relationship between Tilapias individual mass and its dimensions was obtained. Tilapia's depth and thickness were the main dimensions used to determine the Tilapias identity. Three levels of water flow discharging or three profiles of water escaping (superficial) velocity (100, 375 and 500LPM) and two inclinations of grader raceway $\left(5^{\circ}\right.$ and $\left.7^{\circ}\right)$ were investigated. The grader performance was demonstrated by studying the selectivity curve, selection range, individual mass mean selection and grading efficiency for each sieve. Maximum sieve grading efficiency achieved was of $97.87 \%$ at 375 LPM and $5^{\circ}$ grader inclination. Grader operational capacity was of $2000 \mathrm{~kg} / \mathrm{h}$. This productivity can be achieved manually by eight workers for three hours. The behavior of each sieve (allow to pass or retain) during grading process towards each length or individual mass was modeled correspondingly with Logistic and Richard models. Richard model was found to be the best fit model for all the investigated sieves.

KEYWORDS: Grading Process, Sieve Grading Efficiency, Tilapia Fish Ponds, Fish Grader, Sieves Selectivity.

\footnotetext{
* Associate Prof., Ag. Eng. Dept., Fac. of Ag., Kafrelsheikh Univ., Egypt. ** Lecturer, Ag. Eng. Dept., Fac. of Ag., Kafrelsheikh Univ., Egypt.
} 


\section{NOMENCLATURE}

$p \quad$ Split parameter

a Logistic parameter

$b \quad$ Logistic parameter

$L\left(l_{i}\right) \quad$ Likelihood of each length or mass passed

$C_{t i} \quad$ Total fish catch in washing basin for each length or mass, number

$C_{r i} \quad$ Retained number for each length or mass

$C_{p i} \quad$ Passed number for each length or mass

$S\left(l_{i}\right) \quad$ Sieve selectivity for each length or mass, $\mathrm{g}$

$C_{t} \quad$ Total catch number

$T_{u n} \quad$ Total number of fish individual masses retained in the undesired category

$T_{\text {des }} \quad$ Total number of fish individual masses retained in the desired category

$m_{i} \quad$ Individual mass, $\mathrm{g}$

\section{INTRODUCTION}

7 he common fish farming in Egypt is Tilapia (Mono-sex only males). A Common practice is to harvest the entire pond at specified intervals; normally the fish pond is stocked by 24,000 to 35,000 fish per hectare. It is necessary to grade harvested fish according to size for optimal marketing. The process of fish harvest in Egypt is done by evacuating the water from the earthen pond, where fish are moving towards the harvesting canal having some water to maintain the gathering fish. The fish nets are used for lifting them onto washing basin leaving the living Tilapia 30 minutes to do self-washing; the cleaned Tilapia is caught and brought to the sorting table by workers. Other workers stand beside the sorting table and manually collect fish to its specified size box to be ready for marketing. A wooden board placed at the center of sorting table to put four different fish boxes for four fish classes (super style, number 1 , number 2 and the smallest size). The super style is divided into two categories wide super and tight super (Table 1). The workers have faced some difficulties in grading to distinguish manually the Tilapias having same category and the next, for example that wide and tight super or that tight super and number one etc. 
affecting economically specially for first and second categories (the highest prices). On the other hand, the grading process requires experienced workers who rarely found among Egyptian farmers costing 100LE/day.

Table 1: Tilapia's classification in Egyptian markets.

\begin{tabular}{|l|l|l|}
\hline Nominal size & Mass, $\mathrm{g}$ & Length, $\mathrm{mm}$ \\
\hline Wide super & Greater than 300 & Greater than 240 \\
\hline Tight super & 220 to 300 & 230 to 240 \\
\hline Number one & 175 to 220 & 215 to 230 \\
\hline Number two & 100 to 175 & 175 to 215 \\
\hline The finest & Less than 100 & Less than 175 \\
\hline
\end{tabular}

A simple way to grade live fish, particularly fry and fingerlings before stocking, is to use a series of nets with specific mesh sizes or in tanks that requires a good water flow and characteristics (e.g. dissolved oxygen and ammonia etc.) and a series of grading panels installed on grading canal; fish move towards the inflow through the grading panels. The smallest ones should be able to swim against the water current and reach the upstream end of the grading panels. This method does not operate efficiently with harvested fish due to its weakness to swim countercurrently and require a lot of time for the harvesting method used. Several trials used for harvested fish sorting implementing $\mathrm{V}$ shaped section with opened bottom conveyor (Favire, 1989), metal mesh belt conveyor, slider bars and machine vision. Catfish are graded in "live cars" constructed from netting with a mesh size that retains market-sized fish, but allows smaller fish to escape (Huner et al., 1984). Live cars or "socks" are a type of net pen typically $6.1-12.2 \mathrm{~m}$ long, $3.05 \mathrm{~m}$ wide and $1.4 \mathrm{~m}$ deep. Trimpey et al., 2004 designed an in-pond floating UAPB (patent by University of Arkansas at Pine Bluff) grader having grading speed of $105-499 \mathrm{~kg} / \mathrm{min}$; greater than the traditional live-car grader of $0.5-0.6 \mathrm{~kg} / \mathrm{min}$. The UAPB grader consists of a trailer with an integrated 203.2mm, re-lift style water pump; a fish eduction chamber; and a floating, adjustable, horizontal bar grader. The adjustment mechanism and bar spacing gauge calibrated to the parallel bar panel in the grading system. The bar space and corresponding fish size are marked on the gauge to allow users to simply turn the adjustment crank to select for the desired size fish (Heikes, 2007). Engle et al. (2011) studied the 
production and economic effects of in-pond UAPB grader as compared with traditional live car grader. Liang and Chiou, (2009) presented a new method for automatically cleaning and weighing, Tilapias depending on Tilapia's projected area by machine vision. The relationship between mass and projected area was analyzed to present one regression equation used by machine vision. According to Egyptian fish ponds that harvested entirely, it is difficult to apply machine vision grader in the field. Revill and Holst (2004) developed four different designs of sieve nets to catch the target species and assessed the efficiency in capture and loss and the selective properties for each. Karplus et al. (2005) studied the possibility of exploitation of the phototactic (the movement of an entire organism in response to light) and the rheotactic (the tendency of certain living things to move in response to the mechanical stimulus of a current of water) innate responses of guppies (Poecilia reticulate) to induce them to swim through narrow canals. Aydın and Tosunoğlu (2012) analyzed the separation properties of sorting grids for Mediterranean multispecies with 10 and $15 \mathrm{~mm}$ bar spacing for a modified bottom drawing net with a $44 \mathrm{~mm}$ diamond codend. The separation efficiency was differed according to fish species. The Share Each Length's Catch Total (SELECT) method can be used to analyze data where two (or more) types of fishing gear are fished at the same time. Data needed are fishing effort for each gear type, and the size of individuals in the catch. Xu and Millar (1993) provide a description of how the SELECT method can be applied to trap fisheries. Bingzhong et al. (2011) used SELECT method to establish size selectivity of white-spotted conger for each hole of trap tube determining the appropriate size of escape hole. Herrmann et al. (2012) used individual fish morphological characteristics of three redfish species to predict the codend size selection and manufacturing the trawl diamond mesh.

The main objective of this paper is to manufacture a convenient fish grader within tanks for Egyptian fish ponds, and study some variables affect grader efficiency (as water flow discharging and fish grader inclination).

\section{MATERIALS AND METHODS}

17000 samples of different sizes of Oreochromis niloticus males were used in the current experimental work to study the Tilapia inducing to 
move towards the required path (grading raceway). The investigated variables for the Washing Basin with Raceway Grading (WBRG) were related to water flow, canal inclination and fish density. To study the WBGR grader performance, two levels of canal inclination of $5^{\circ}$ and $7^{\circ}$ and three different water flow discharging of 100, 375 and 500LPM were investigated. Aerated water flowed into the grading canal via a flow meter that showed a steady flow. The regression model required to establish the relationship between length, depth, thickness and mass to calculate sieves sizes. A fundamental proposition in size selectivity work was formulated by Baranov (1948) and has become known as the "principle of geometrical similarity". It states that the selectivity/retention of fish depends only on the fish geometry relative to the mesh geometry. So the sieves openings dimensions (width and height) were determined according to the Tilapias morphology (thickness and depth) respectively (Table 2 ).

Table 2: Sieves sizes corresponding to each category.

\begin{tabular}{|c|c|c|c|}
\hline $\begin{array}{c}\text { Sieves } \\
\text { number }\end{array}$ & $\begin{array}{c}\text { Width, mm } \times \\
\text { Height, mm }\end{array}$ & $\begin{array}{c}\text { Predicted mean } \\
\text { selection range, } g\end{array}$ & $\begin{array}{c}\text { Nominal size } \\
\text { retained }\end{array}$ \\
\hline 1 & $40 \times 90$ & 260 & Wide super \\
\hline 2 & $40 \times 86$ & 240 & Tight super \\
\hline 3 & $35 \times 75$ & 210 & Number 1 \\
\hline 4 & $30 \times 78$ & 186 & Number 2 \\
\hline
\end{tabular}

The WBRG grader consists of:

1. Washing basin having four inlets of aerated water through four venturis and other four inlets with venturis for the grader canal to ensure a homogenous distribution of aerated water within water column inside the grader (Figure 1). The water was pumped by $735 \mathrm{~W}$ water pump continuously with flow rate of 60LPM. The grader operational capacity was $2000 \mathrm{~kg} / \mathrm{h}$. The washing basin was designed to be convenient for the harvested fish and relieve the catching stresses. After 30 minutes the organisms can move freely in the grader, an automatic valve $7.6 \mathrm{~cm}$ in diameter was installed at the grader tail and opened automatically to discharge the entire water.

2. Inclined sorting canal with inclination of $5^{\circ}$.

3. Four plates of stainless steel sorting grids.

4. Five evacuating gates for the graded Tilapias. 
The current research work was carried out in a fish pond located in Elhamoul city, Kafr Elsheikh governorate, Egypt during summer season 2012. The experimental study was performed to determine the optimum conditions of water flow discharge and grader raceway inclination on the individual mass mean selection (Equation 1), selection range, grading efficiency (Equation 2) and determining the selectivity curve (the relationship between fish individual mass and retention probability) for each sieve, under different independent variables comparing with different models (SELECT model, Richard model and Logistic model (three-parameter model)).

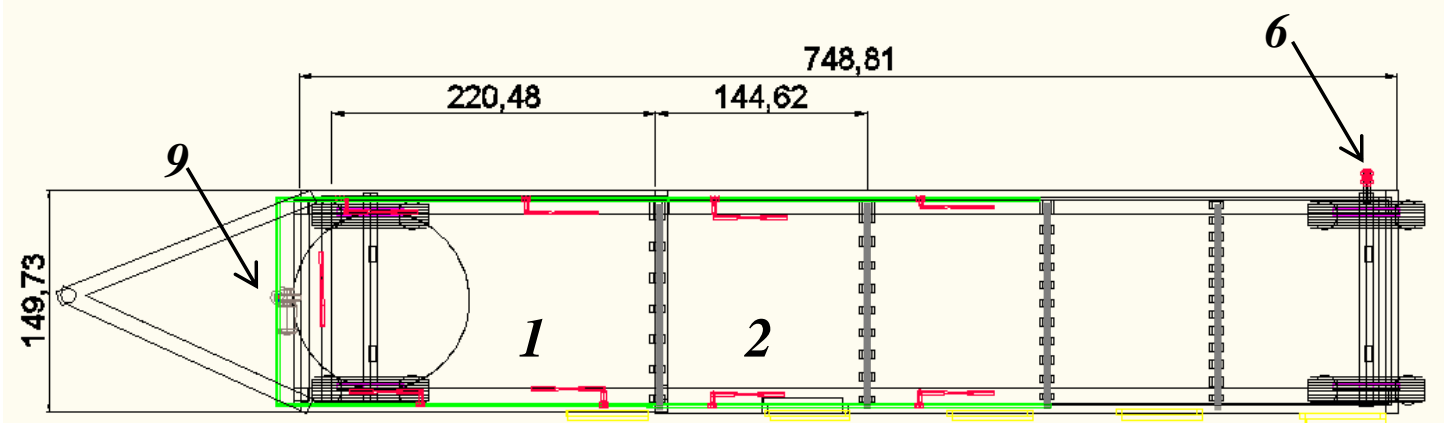

\begin{tabular}{|l|l|}
\hline 1 & Washing basin \\
\hline 2 & Grading raceway \\
\hline 3 & $\begin{array}{l}\text { Grading chambers } \\
\text { evacuated gates }\end{array}$ \\
\hline 4 & $\begin{array}{l}\text { Fresh aerated water } \\
\text { inlets through the } \\
\text { venturis pipes }\end{array}$ \\
\hline 5 & Sieves plates \\
\hline 6 & Water discharging valve \\
\hline 7 & WBRG chassis \\
\hline 8 & WBRG draw point \\
\hline 9 & 1hp water pump \\
\hline 10 & $\begin{array}{l}\text { Water supply line } \\
\text { (3.81cm in diameter) }\end{array}$ \\
\hline
\end{tabular}

Dimensions in cm

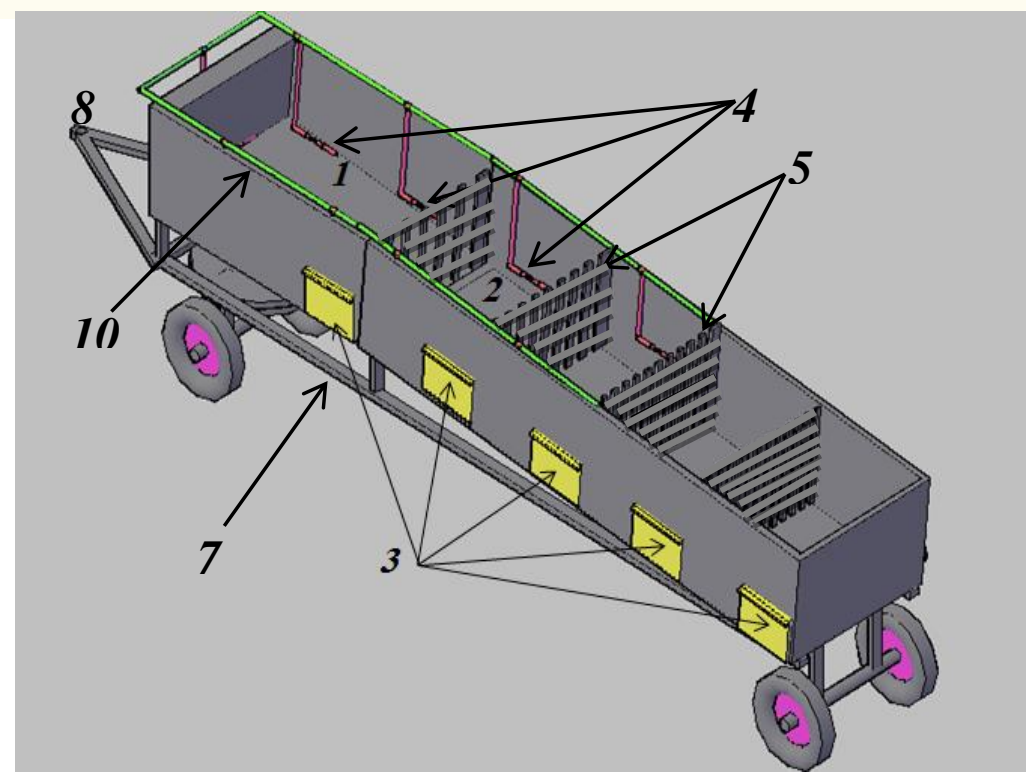

Figure 1: Perspective and engineering drawing of the manufactured Washing Basin with Raceway Grading Fish Grader type. 
PROCESS ENGINEERING

$$
l_{50 \%}=\frac{\sum_{i=1}^{C_{t}} m_{i} \times C_{t i}}{\sum_{i=1}^{C_{t}} C_{t i}}
$$

Where $l_{50 \%}$ is the individual mass or length mean selection.

$$
\text { Sieve grading efficiency, } \%=\frac{T_{\text {des }}}{T_{\text {des }}+T_{\text {un }}} \times 100
$$

The undesired individual masses $\left(T_{u n}\right)$ is the summation of desired individual masses found in other categories (incorrect category) and the undesired individual masses found in the category under investigation. After calculating the grading efficiency of each sieve (SGNo.i) by Equation 2, the grader grading efficiency (GGE) is the mean of grading efficiency for the four sieves can be calculated by Equation 3.

$$
\mathrm{GGE}=\frac{\sum_{i=1}^{4} S G N o . i \times R n . i}{\sum_{i=1}^{4} \text { Rn. } i} \times 100
$$

Where $R n . i$ is the number of Tilapias retained by sieve number $i$. The simplex algorithm was used to maximize the log-likelihood function (Nelder and Mead, 1983). The values of Akaike's Information Criterion (AIC) were then computed (Akaike, 1974) to determine the most appropriate selectivity model of the three described equations. The bestfit model was that with the smallest AIC value (Hiramatsu, 1992). Sardà et al. (2006) used the SELECT model (Millar, 1992) to fit data to Logistic and Richard's functions. For the square mesh experiment, the probability that a fish of length $l$ entering the grader raceway will be retained by the net was assumed to be:

$$
s\left(l_{i}\right)=\frac{p \exp (a+b l)}{[1-p+\exp (a+b l)]}
$$

The values of the parameters $\mathrm{p}$, $\mathrm{a}$, and $\mathrm{b}$ were estimated by maximizing the log-likelihood function (Tokai, 1997). The parameter $\mathrm{p}$ represents here the fishing intensity (Millar and Fryer, 1999). Parameters a \& b 
were used to calculate the $50 \%$ selection length, $L_{50 \%}$, and the selection range, SR. The best model fits (Table 2) were found by testing the hypotheses $\mathrm{H}_{0}: \mathrm{p}=0.5$ (equal split) and $\mathrm{H}_{1}: \mathrm{p} \neq 0.5$ (estimated split) using Pearson's chi-square statistic. For the sorting grid experiment, the equation used to calculate the best parameter values for the experimental sorting grids was based on:

$$
s\left(l_{i}\right)=\frac{\exp (a+b l)}{[1+\exp (a+b l)]^{1 / \delta}}
$$

The value of $\delta$ is a measure of the asymmetry of the selection curve around $L_{50 \%}$.

\section{MODEL CALCULATIONS}

1. Calculating initial values of parameters $\mathbf{a}$ and $\mathbf{b}$

a. $50 \%, 75 \%$ and $25 \%$ selectivity length estimated roughly by eye

$$
l_{50 \%}, l_{75 \%} \operatorname{and} l_{25 \%}
$$

b. Selection range estimated roughly by eye

$$
S . R .=l_{75 \%}-l_{25 \%}
$$

c. Initial value of Logistic parameter, a calculated from

$$
a=l_{50 \%} \times-b
$$

In Richard model the mean length $\left(l_{50 \%}\right)$, can be calculated by

$$
l_{50}=\frac{\operatorname{logit}\left(\mathrm{P}^{5}\right)-a}{\mathrm{~b}}
$$

Where $\mathrm{p}$ is a number between 0 and 1 (assumed initially 0.5)

$$
\operatorname{logit}(p)=\log _{e}\left(\frac{p}{1-p}\right)
$$

d. Initial value of Logistic parameter, b calculated from 


$$
b=\frac{2 \ln 3}{S . R .}
$$

And for Richard model

$$
b=\frac{\operatorname{logit}\left(0.75^{5}\right)-\operatorname{logit}\left(0.25^{5}\right)}{S . R .}
$$

e. Split parameter, $p$ estimated.

\section{Calculating sum of log-likelihood as an objective function}

a. Total catch number of each length class

b. Proportion of each length retained for each sieve to total catch number

$$
C_{r i} \%=\frac{C_{r i}}{\left(C_{r i}+C_{p i}\right)}
$$

c. Retention probability of each length estimated from logistic equation by Equation 1 and 2 .

d. Likelihood of each length

$$
L\left(l_{i}\right)=\operatorname{COMBIN}\left(C_{t i} ; C_{r i}\right) \times S\left(l_{i}\right)^{C_{r i}} \times\left[\left(1-S\left(l_{i}\right)\right)^{C_{p i}}\right]
$$

e. Summation of log likelihood of each length

$$
S L=\sum_{i=1}^{c_{t}} \ln \left[L\left(l_{i}\right)\right]
$$

\section{Model deviance and standard errors}

a. Standardized residual of each length

$$
\begin{aligned}
& \operatorname{DR}\left(l_{i}\right) \\
& =\operatorname{IF}\left[C_{t i}-C_{i \eta_{0}}>0 ; 1 ;-1\right] \\
& \times \sqrt[2]{\left[\left[2 \times C_{t i} \times\left(C_{\eta 0} \times I F\left(C_{i \gamma_{0}}>0 ; \ln \left(\frac{C_{i \gamma_{0}}}{S\left(l_{i}\right)}\right) ; 0\right)+\left(1-C_{i \gamma_{0}}\right) \times I F\left(C_{\eta 0}<1 ; \ln \left(\frac{\left(1-C_{i \psi_{0}}\right)}{1-S\left(l_{i}\right)}\right) ; 0\right)\right)\right]\right.}
\end{aligned}
$$


b. The deviance of the whole model

$$
M D=\sum_{i=1}^{n=c_{\mathrm{t}}}\left(D R\left(l_{i}\right)\right)^{2}
$$

c. Value of Akaike's information criterion (AIC)

$$
\mathrm{AIC}=(-2 \times \mathrm{SL})+(2 \times 2)
$$

Where the minimum AIC indicates the appropriate model equation

d. Standard errors of model parameters

$$
\begin{gathered}
\text { Fisher information matrix }=\left[\begin{array}{lll}
I_{11} & I_{12} & I_{13} \\
I_{21} & I_{22} & I_{23} \\
I_{31} & I_{32} & I_{33}
\end{array}\right] \\
I_{11}=\sum_{i=1}^{n=c_{t}} \frac{C_{t i} \times\left(d\left(l_{i}\right)\right)^{2}}{S\left(l_{i}\right) \times\left(1-S\left(l_{i}\right)\right)} \\
d\left(l_{i}\right)=\frac{p \times(1-p) \times E X P\left(a+b \times l_{i}\right)}{\left(\left(1-p+E X P\left(a+b \times l_{i}\right)\right)^{2}\right)} \\
h\left(l_{i}\right)=\frac{E X P\left(a+b \times l_{i}\right) \times\left(1+E X P\left(a+b \times l_{i}\right)\right)}{\left(\left(1-p+E X P\left(a+b \times l_{i}\right)\right)^{2}\right)} \\
I_{12}=I_{21}=\sum_{i=1} \frac{C_{t i} \times l_{i} \times\left(d\left(l_{i}\right)\right)^{2}}{S\left(l_{i}\right) \times\left(1-S\left(l_{i}\right)\right)}
\end{gathered}
$$




$$
\begin{gathered}
I_{22}=\sum_{i=1}^{n=c_{t}} \frac{C_{t i} \times\left(l_{i}\right)^{2} \times\left(d\left(l_{i}\right)\right)^{2}}{S\left(l_{i}\right) \times\left(1-S\left(l_{i}\right)\right)} \\
I_{13}=I_{31}=\sum_{i=1}^{n=c_{t}} \frac{C_{t i} \times d\left(l_{i}\right) \times h\left(l_{i}\right)}{S\left(l_{i}\right) \times\left(1-S\left(l_{i}\right)\right)} \\
I_{23}=I_{32}=\sum_{i=1}^{n=c_{t}} \frac{C_{t i} \times l_{i} \times d\left(l_{i}\right) \times h\left(l_{i}\right)}{S\left(l_{i}\right) \times\left(1-S\left(l_{i}\right)\right)} \\
I_{23}=I_{32}=\sum_{i=1}^{I_{33}}=\sum_{i=1}^{n=c_{t}} \frac{C_{t i} \times\left(h\left(l_{i}\right)\right)^{2}}{S\left(l_{i}\right) \times\left(1-S\left(l_{i}\right)\right)} \\
S\left(l_{i}\right) \times\left(1-S\left(l_{i}\right)\right)
\end{gathered}
$$

Covariance matrix of estimated $a$ and $b$

$$
\left[\begin{array}{lll}
I_{11} & I_{12} & I_{13} \\
I_{21} & I_{22} & I_{23} \\
I_{31} & I_{32} & I_{33}
\end{array}\right]^{-1}
$$

Standard error of estimated parameter $\mathrm{a}$ and $\mathrm{b}$

$$
\begin{aligned}
& S E(a)=\sqrt{I_{11}} \\
& S E(b)=\sqrt{I_{22}} \\
& S E(p)=\sqrt{I_{33}}
\end{aligned}
$$




\section{RESULTS AND DISCUSSION}

\section{Tilapias morphology}

Before thinking in manufacturing the Tilapias grader, Tilapias morphology was studied acknowledged the relationship between length, depth and thickness and individual mass (Figure 2).

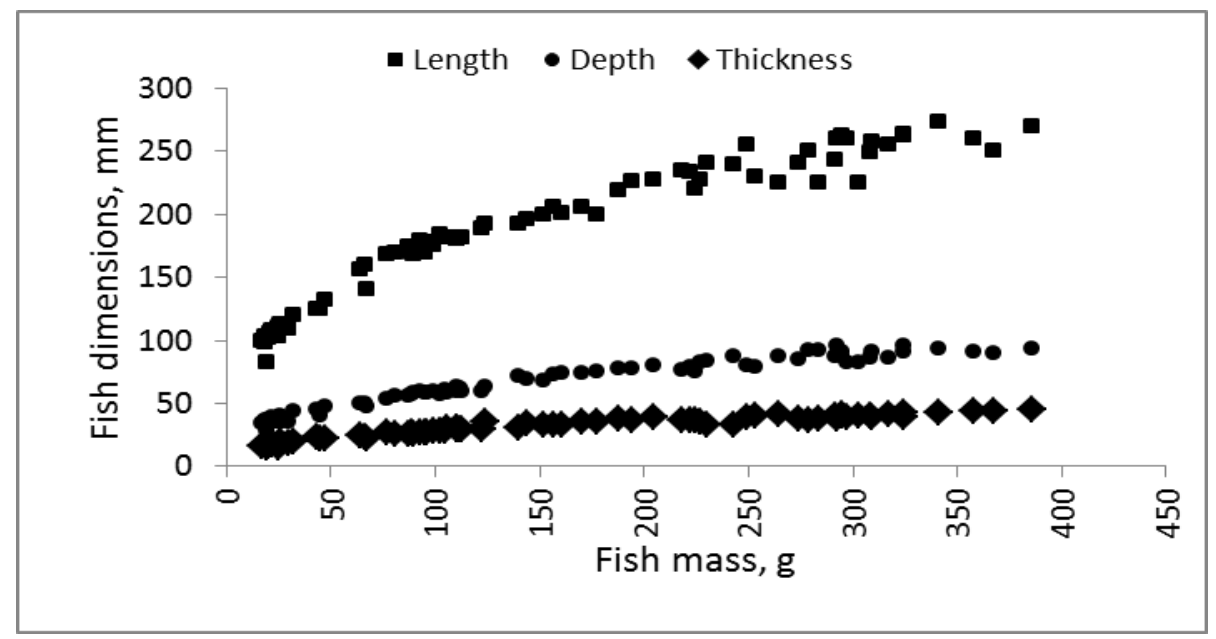

Figure 2: Tilapias dimensions accordance with their individual masses.

The developed equation (Equation 30) can be used to predict the individual Tilapias mass based on its length, depth and thickness. Figure 3 compares the experimental data with those predicted by Equation 30 for Tilapia samples. The prediction used the equation showed Tilapia mass (TM) values banded along the straight line, which showed the

$$
T M=0.000279 \times L^{1.3002} \times D^{0.77226} \times T^{0.87157} \quad \mathrm{R}^{2}=0.988
$$

suitability of the TM equation in describing Tilapia individual mass.

Where TM is the Tilapia individual mass, $\mathrm{g}$; $\mathrm{L}$ is the Tilapia length, mm; $\mathrm{D}$ is the Tilapia depth, $\mathrm{mm}$; and $\mathrm{T}$ is the Tilapia thickness, $\mathrm{mm}$. Generally Tilapias length was used as an alternative measure for size, the following equation can determine Tilapias individual mass according to their lengths only (Equation 31).

$$
T M=0.00003 L^{2.9155} \quad \mathrm{R}^{2}=0.982
$$




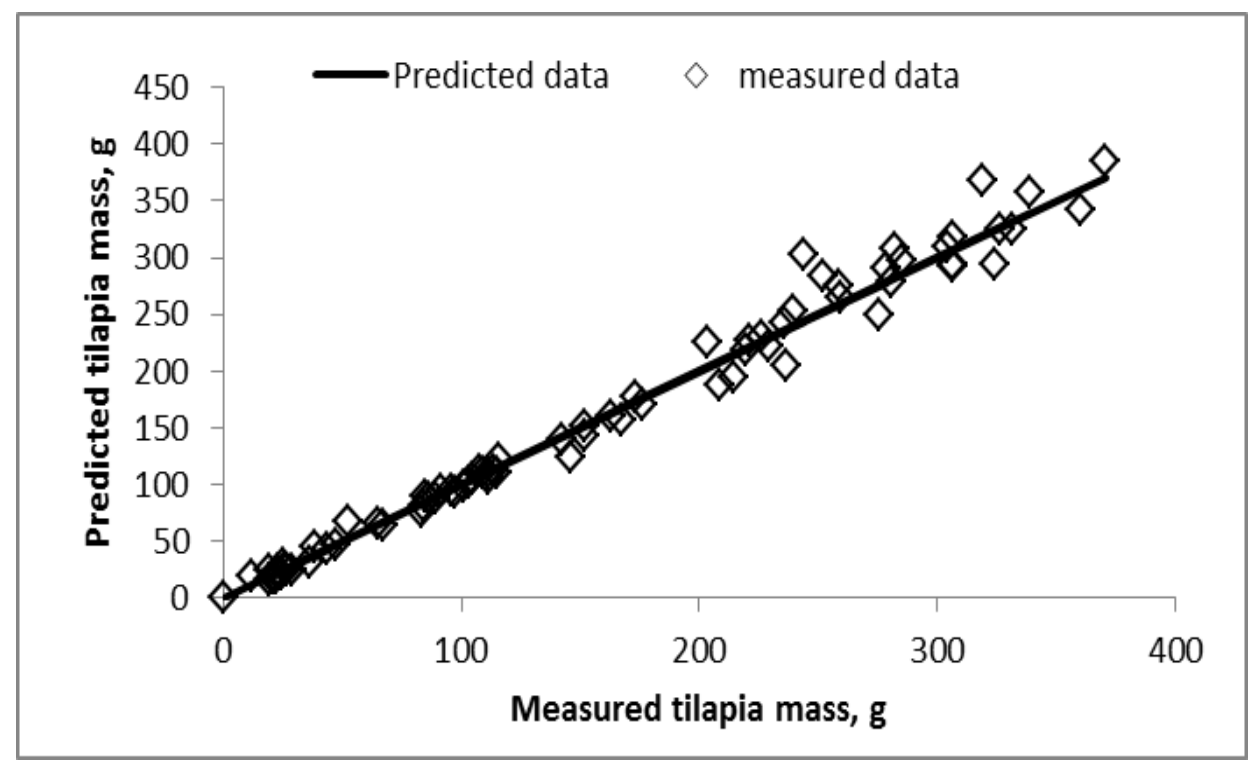

Figure 3: Scatter distribution of the measured versus the predicted tilapia individual mass by Equation 30 .

\section{Grader performance and sieves selectivity}

The retention proportion (selectivity) by sieves for each individual mass of Tilapias was studied (Figure 4). The results demonstrate that the retention proportion of each sieve is a function of grader's raceway inclination and water flow discharging. The retention proportion of each sieve increases with body individual mass ignoring the interferences between the sieves (Figure 4). For sieve number1, as fish individual mass increases from 285 to $305 \mathrm{~g}$, the retention proportion increases from 0.0120 to 0.9107 , respectively to be totally retained. Individual masses that totally retained at $5^{\circ}$ inclination and 375LPM water discharging were greater than 305 , from 235 to 285 , from 200 to 210 and from 180 to $185 \mathrm{~g}$ for sieves number 1, 2, 3 and 4, respectively. These individual masses were decreased as water flow discharging increases to 500LPM, at $5^{\circ}$ inclination, being greater than 295 , from 225 to $265 \mathrm{~g}$ for sieves number 1 and 2 only, and there were no individual masses that totally retained by sieves number 3 and 4 . 

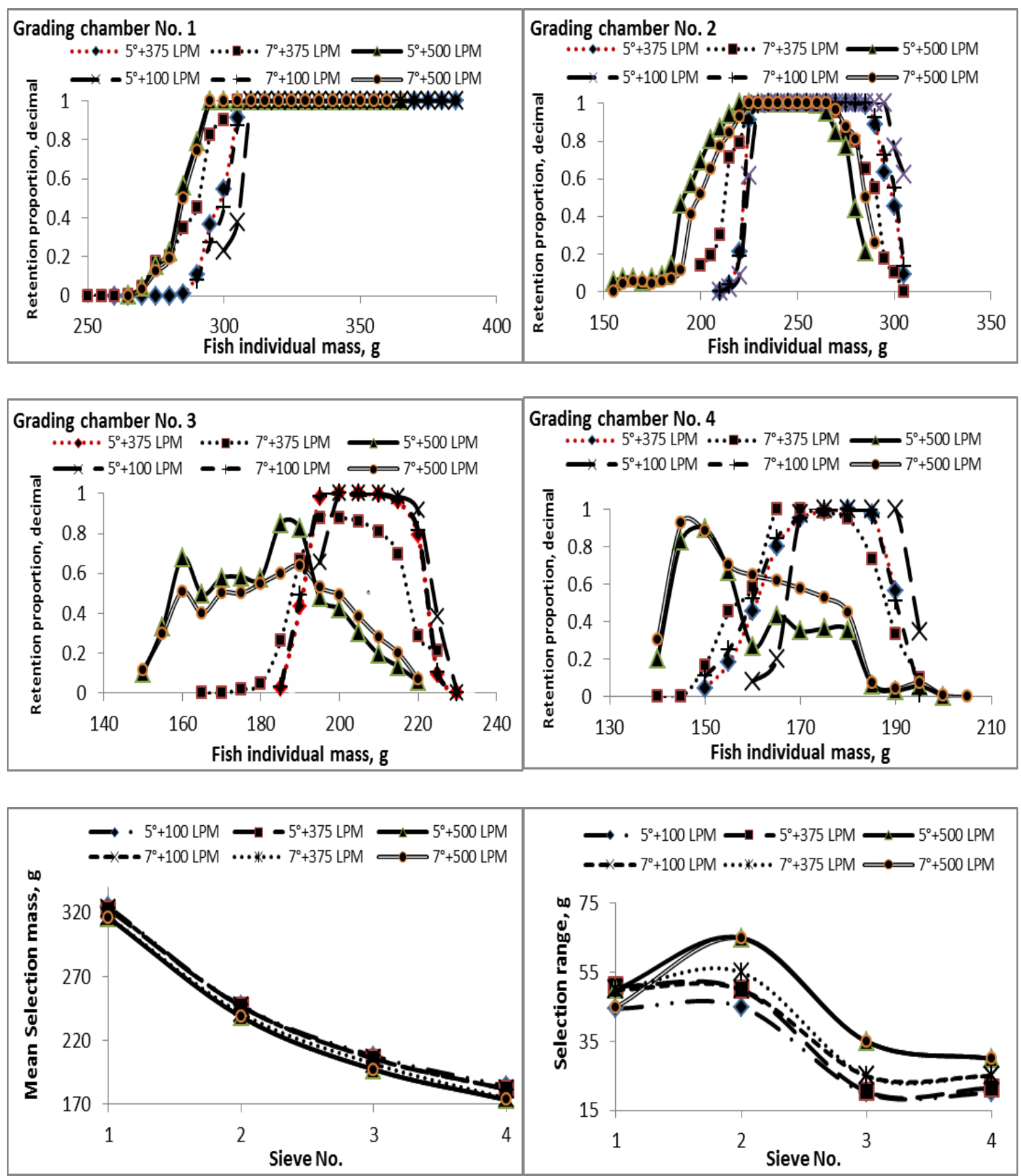

Figure 4: The effect of grader's raceway inclination and water flow discharging rate on the retention proportion (selectivity curve), selection range and mean selection mass for each fish individual mass. 
Sieves number 3 and 4 were the most affected by water flow discharging having higher deformations on their selectivity curves at 500LPM for the both inclinations $5^{\circ}$ and $7^{\circ}$ due to the highest superficial water velocity profile obtained inside the raceway grader (Figure 5). Maximum retention proportions obtained for sieves number 3 and 4 were 0.85 and 0.90 at fish individual masses of 220 and $185 \mathrm{~g}$, respectively. For the given individual masses class, an increase of sieve number (decreasing the openings hole) increments their retention proportion. For fish individual mass of $170 \mathrm{~g}$, as sieve number increases from 3 to 4 , the retention proportion raises from 0.0179 to 0.9820 . The treatments affect significantly $(\mathrm{P}<0.19)$ fish individual mass retention proportion.

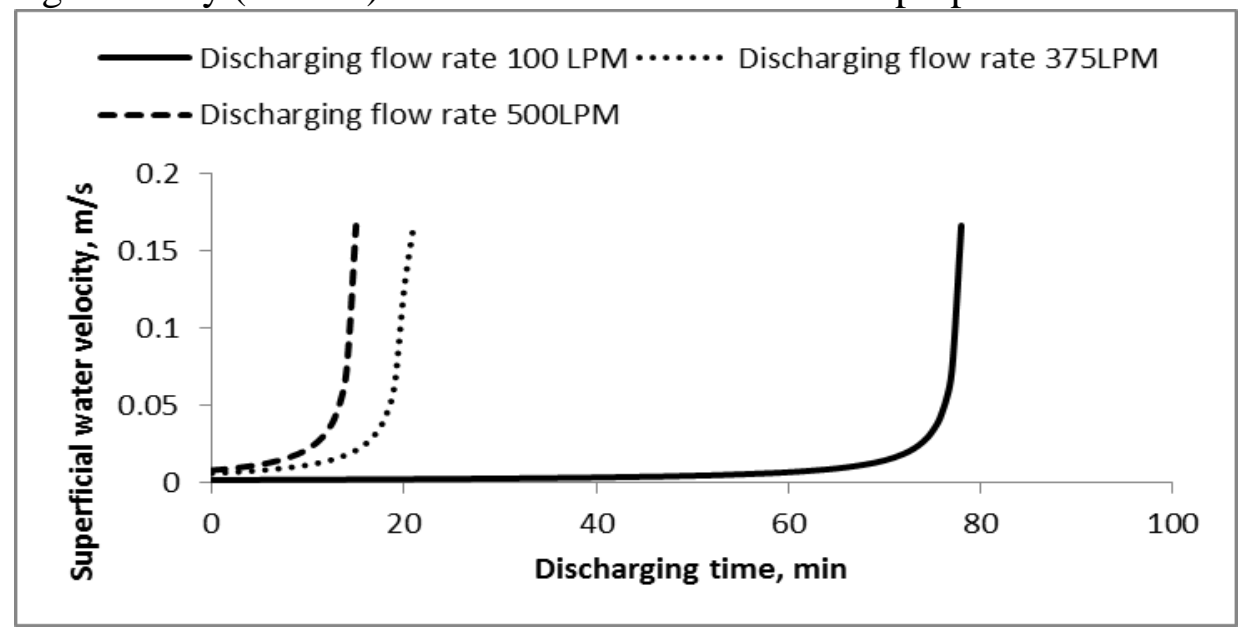

Figure 5: Superficial water velocity profiles of the three flow discharging rates of 100, 375 and 500LPM.

The parameters under study affect significantly $(\mathrm{P}<0.01)$ individual mass mean selection. However selection range increases at higher water discharging. For sieve number 2, selection range expands from 45 to $65 \mathrm{~g}$ by raising the value of water discharge or water escaping velocity (superficial water velocity) due to Tilapias behavior moving through sieves, most Tilapias are hesitant to move towards sieves and need some time checking the safety to pass or be retained (Figure 6). Higher water escaping velocity from the grader does not give the chance for Tilapias swimming through sieves. Egyptian fish ponds are harvested entirely after six months of culturing, the majority of size (marketable size) 
acquired is from 200 to $300 \mathrm{~g}$ that is retained by sieve number 2 recording the highest total retained number of 14116 at $7^{\circ}$ inclination and 100LPM water flow discharging. The accumulated retained percent jumped from 4.66 to $74.37 \%$ by sieve number 2 for the same reason at $5^{\circ}$ and 375LPM (Figure 6).

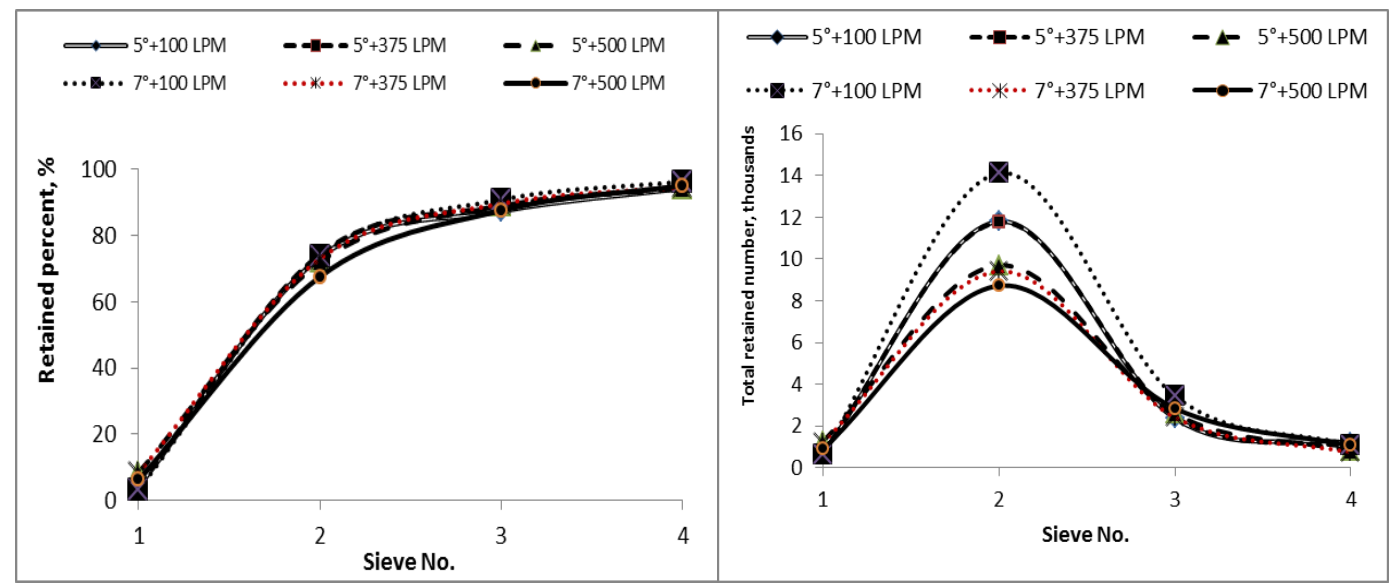

Figure 6: Estimated total retained number and retained percent of Tilapias for each sieve.

\section{Category interference and sieve grading efficiency}

There are two types of interference between each two sieves (the interference with above and the interference with below) for example if the sieve number 2 has a proportion of some fish individual masses retained by sieve number 1 is called interference with above and on the other side if the sieve number 2 has a part of some fish individual masses retained by sieve number 3 is called interference with below. In this grader only the sieve number 1 has not interference with above. It was observed that there is interference between sieve number 1 and 2 for the lowest sizes only. However the other sieves number 2, 3 and 4 there are interferences in fish individual masses retained between them makes one is a complementary with before and next. As interference of fish individual mass between sieves decreases, the fish grader has higher grading efficiency and there is no a significant interference between categories. Raceway inclination of $5^{\circ}$ with water discharging of 100LPM recorded the lowest interference of fish individual masses between sieves number $1 \& 2,2 \&$ 3 and $3 \& 4$ to be 7,15 and $5 \mathrm{~g}$, respectively (Figure 7). The desired individual masses should retained by sieves were listed in Table 2 . 


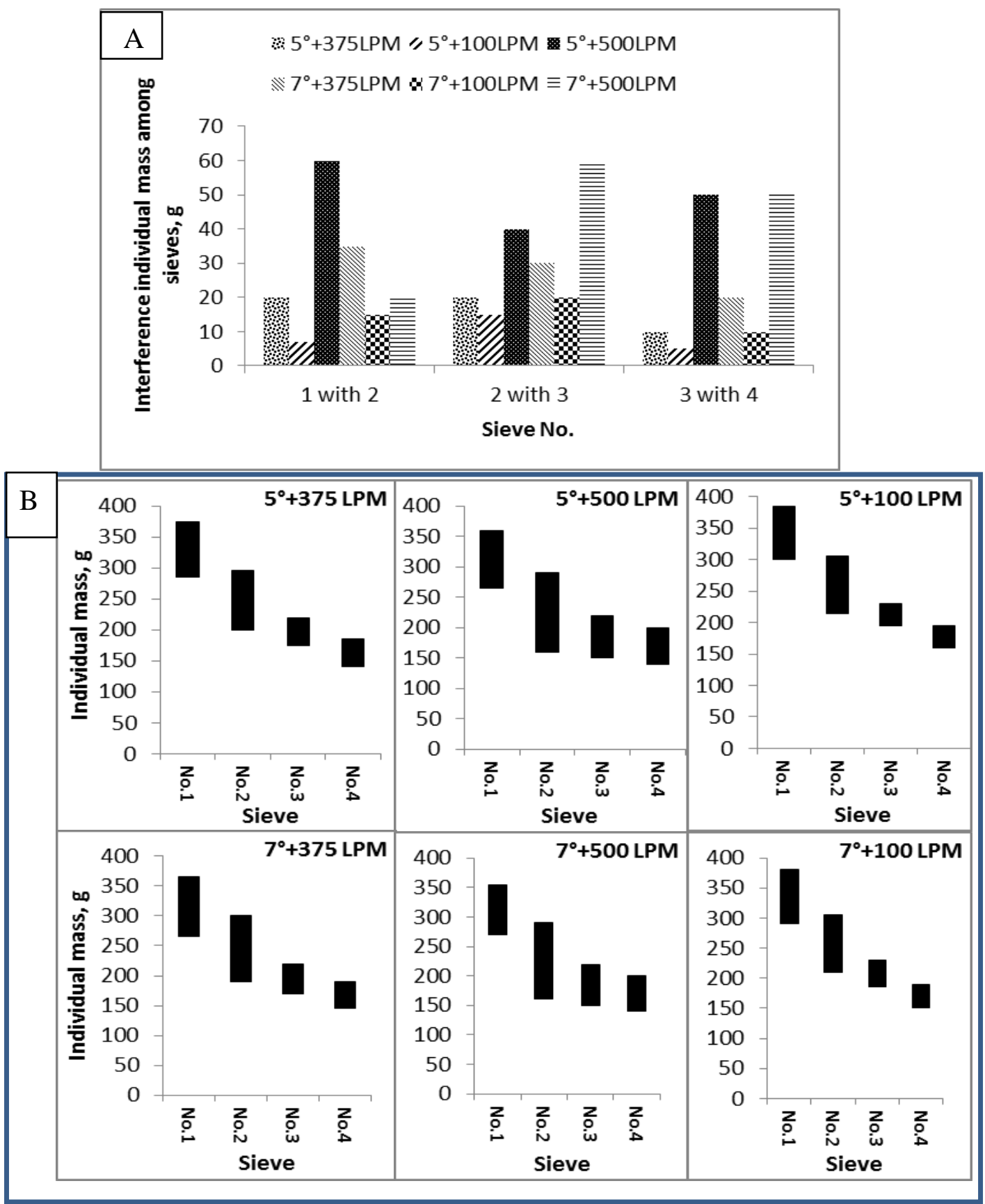

Figure 7: The effect of raceway inclination and water flow discharging on the interference of fish individual mass among sieves (A) which calculated from six histograms below (B). 
Grading efficiency measures the deviation for each sieve getting specific category. Sieve grading efficiency for sieves number 1 and 2 are 96.36 and $97.87 \%$, respectively, where sieve number 4 recorded the lowest grading efficiency due to Tilapias dimensions differences between the Third and Fourth categories are the smallest to distinguish it physically by sieves. The highest grader grading efficiency of $92.1 \%$ was obtained at $5^{\circ}$ with $375 \mathrm{LPM}$ (Figure 8 ).

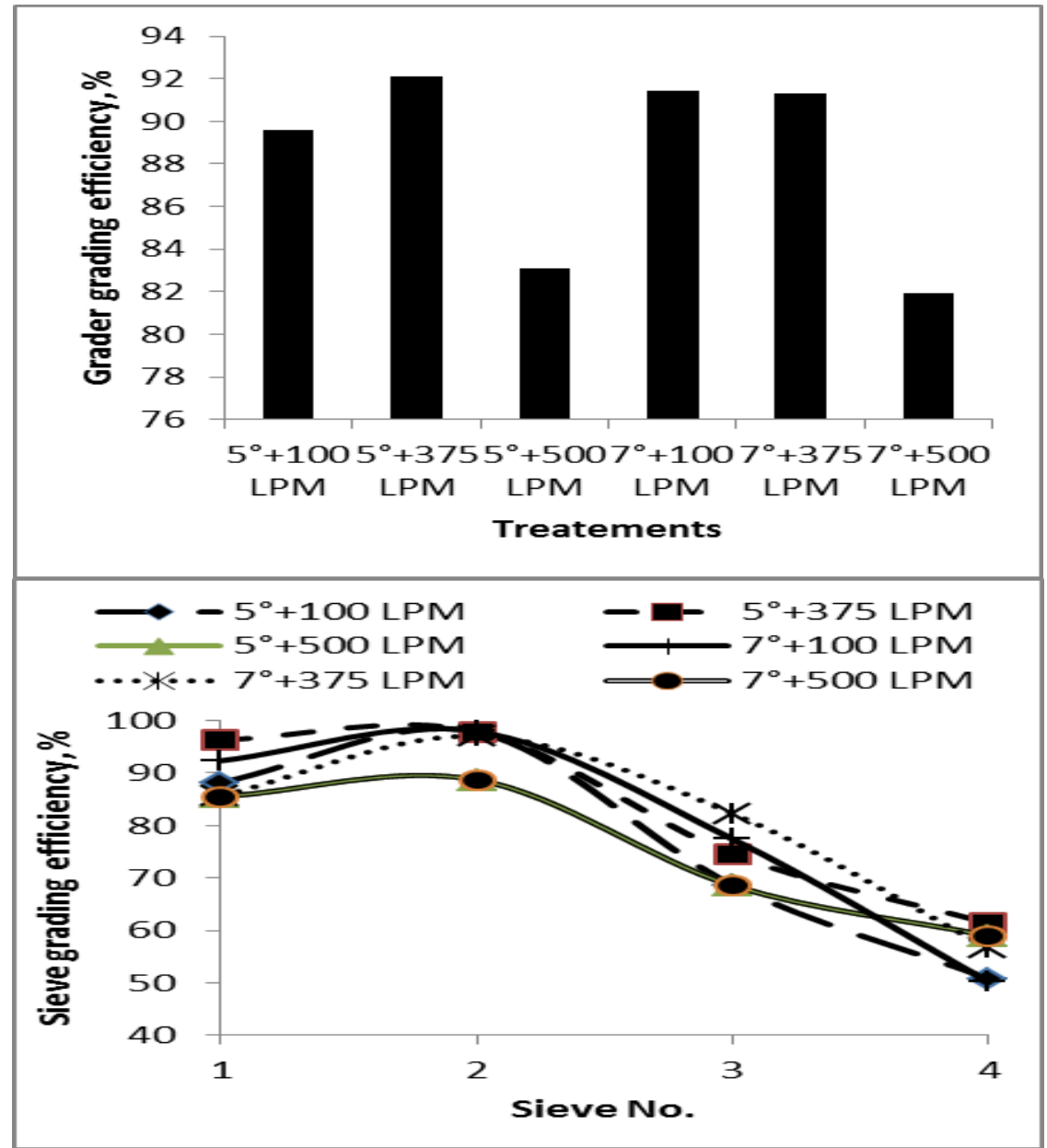

Figure 8: Grader and sieves grading efficiency at different levels of water flow discharging and inclination of fish grader.

\section{Sieves modeling}

Sieve nets have been mandatory in Egyptian fishery. However the evaluation techniques have not been applied and do not meet with the 
European Commission Fisheries Technical Conservation Regulation 850/98. This evaluation technique measure has been implemented on this grader as a fishery gear showing the selectivity curve for each sieve for further modifications in size and shape if required for other purposes such as fishing in seas. The selectivity analysis in terms of the nondimensional parameter $R$ (retention proportion) reveals that, for each sieve, a single selectivity curve describes accurately the data of each. Sieve number 1 was the best modeled by three parameters-Logistic curve and Richard curve (Figure 9). However as general the Richard model was the best fitting model for all sieves. Table 3 indicates the parameters model for each sieve. Table 4 shows the values of AIC minimum AIC value indicates the appropriate equation for each sieve.
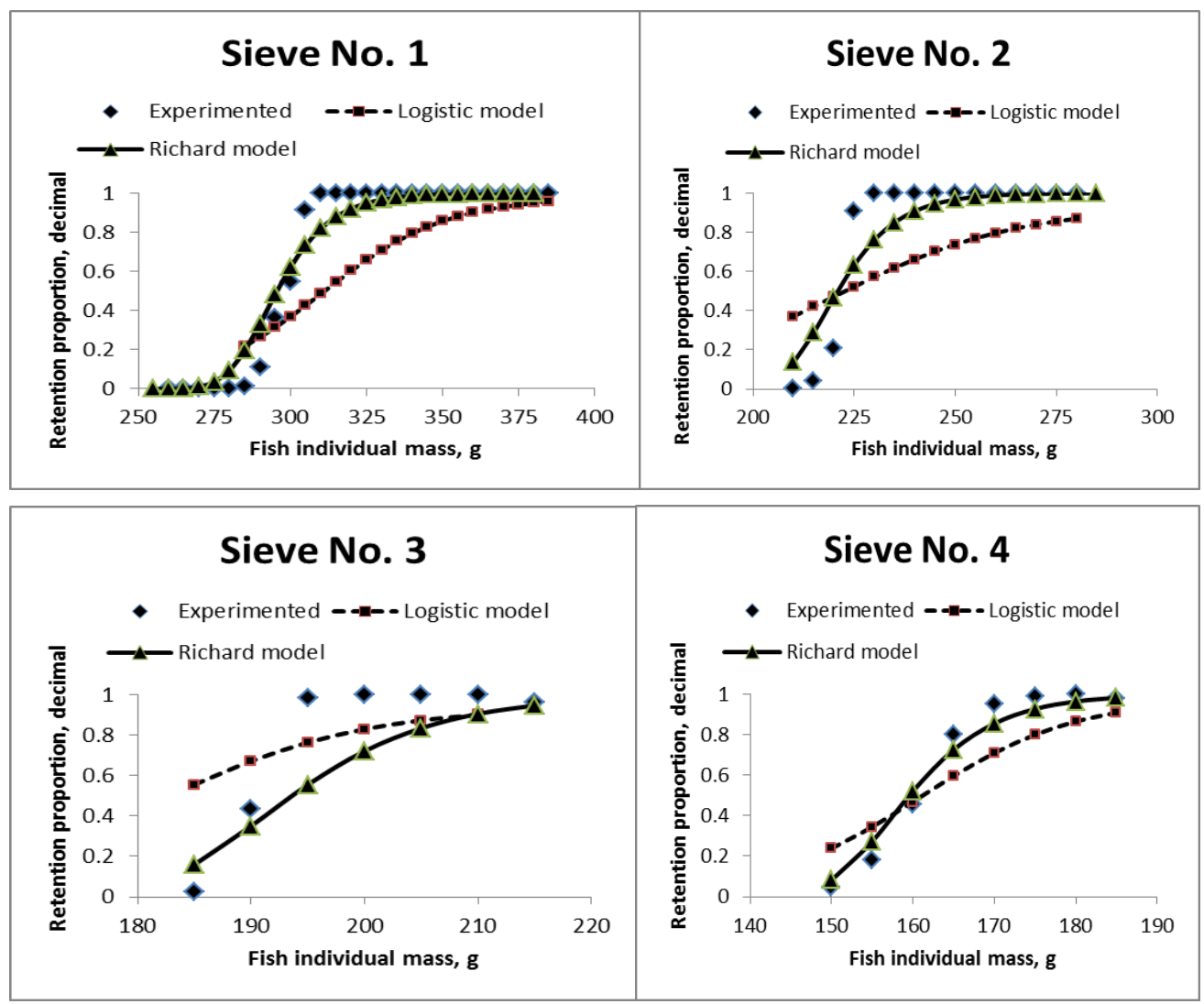

Figure 9: The fit of three parameters of Logistic model and that of Richard model. The dots represent the proportion of fish that were retained in each individual mass class. 
Table 3: The best fitting selectivity models and parameter (a,b,p and $\bar{\delta}$ ) values with standard errors (SE) indicated.

\begin{tabular}{|l|l|l|l|l|l|l|l|}
\hline $\begin{array}{l}\text { Sieves } \\
\text { number }\end{array}$ & Model & $\mathrm{a}$ & $(\mathrm{SE})$ & $\mathrm{b}$ & $(\mathrm{SE})$ & $\mathrm{p}, \delta$ & $(\mathrm{SE})$ \\
\hline No.1 & Logistic & -19.12 & 2.207 & 0.049 & 0.0074 & $\mathrm{P}=0.98$ & 0.0662 \\
\hline No.2 & Logistic & -12.30 & 1.506 & 0.044 & 0.0072 & $\mathrm{P}=0.93$ & 0.0188 \\
\hline No.3 & Logistic & -22.80 & 2.007 & 0.110 & 0.0110 & $\mathrm{P}=0.94$ & 0.0077 \\
\hline No.4 & Logistic & -20.80 & 5.115 & 0.105 & 0.0311 & $\mathrm{P}=0.98$ & 0.0227 \\
\hline No.1 & Richard & -25.20 & 24.840 & 0.090 & 0.0860 & $\delta=0.21$ & 0.0059 \\
\hline No.2 & Richard & -21.21 & 13.036 & 0.106 & 0.0610 & $\delta=0.15$ & 0.0008 \\
\hline No.3 & Richard & -20.60 & 55.843 & 0.120 & 0.2997 & $\delta=0.10$ & 0.0031 \\
\hline No.4 & Richard & -20.60 & 101.070 & 0.145 & 0.6674 & $\delta=0.11$ & 0.0040 \\
\hline
\end{tabular}

Table 4: Values of AIC computed in the two equations of selectivity curve for each sieve.

\begin{tabular}{|l|c|c|}
\hline \multirow{2}{*}{ Sieves number } & \multicolumn{2}{|c|}{ Values of AIC for selectivity curve equations } \\
\cline { 2 - 3 } & Equation 4 & Equation 5 \\
\hline No.1 & 735.7568 & 228.3534 \\
\hline No.2 & 4109.2730 & 804.1876 \\
\hline No.3 & 4387.0420 & 1320.0920 \\
\hline No.4 & 2032.4720 & 822.4765 \\
\hline
\end{tabular}

\section{CONCLUSIONS}

Washing Basin with Raceway Grading grader used four sieves and water current to classify the harvested Tilapias immediately within fish ponds into five nominal categories (wide super, tight super, number one, number two and the finest). The harvested Tilapias were refreshed during 30 minutes in washing basin with aerated water to relief all stresses occurred during netting. One orifice $38.1 \mathrm{~mm}$ was set to control water level inside the grader. Water pump is turned off simultaneously as discharging valve was opened. The refreshed Tilapias are starting to swim tracing the withdrawn water within raceway grading channel. Water discharging and raceway inclination affect grader performance. The optimum operating conditions achieved were at $5^{\circ}$ and 375LPM. Grader grading efficiency was $92.01 \%$ with productivity of $2000 \mathrm{~kg} / \mathrm{h}$. Individual mass mean selections obtained by grader for the nominal 
categories were $322.7,246.8,206,182$ and $126.9 \mathrm{~g}$ respectively. Selection range, $g$ and grading efficiency, \% for sieves number 1 to 4 were 51 and 96.33, 50 and 97.87, 20.5 and 74.496 and $21.5 \mathrm{~g}$ and $61.366 \%$, respectively. $70 \%$ of Tilapias have been retained by sieve number 2 ; it means that $73 \%$ of the harvested pond was categorized as super style for optimal marketing, and the interferences among nominal categories was ranged from 10-20g. Richard model was the most reliable model which can express the selectivity curve for each sieve.

\section{REFERENCES}

Akaike, H. 1974. A new look at the statistical model identification. IEEE Trans. Automat. Contr., AC-19: 716-723.

Aydın, C. and Z. Tosunoğlu. 2012. Evaluation of sorting grids for deepwater rose shrimp (Parapenaeus longirostris) in the Eastern Mediterranean demersal trawl fishery. Journal of Applied Ichthyology. 28: 102-106.

Baranov, F. I. 1948. Theory and assessment of fishing gear. Ch. 7: Theory of fishing with gill nets. Pishchepromizdat, Moscow. 45 p. (Translation from Russian by Ontario Department of Lands and Forests, Maple. Ont.).

Bingzhong, Y., Yanli, T. and L. Zhenlin. 2011. Selectivity of escape-hole size in tube traps for whitespotted conger myriaster. Chinese Journal of Oceanology and Limnology. 29 (5): 1041-1047.

Engle, C. R., B. Southworth, P. O. Sudhakaran and A. Nanninga. 2011. Production and economic effects of in-pond grading of channel catfish. Aquacultural Engineering 45, 1-8.

Favire, C. 1989. Machine for grading and sorting fish, in particulary fish from the salmonidae family. United States patent number $4,854,455$.

Heikes, D. 2007. Components and Use of an In-Pond Fish Grading System. Sothern Regional Aquaculture Center. SRAC publication No.3901.

Herrmann, B., M. Sistiaga, K. N. Nielsen and R. B. Larsen. 2012. Understanding the Size Selectivity of Redfish (Sebastes spp.) in North Atlantic Trawl Codends. J. Northw. Atl. Fish. Sci., 44: 1-13. Hiramatsu, K. 1992. A statistical study of fish population dynamics using maximum likelihood method. Parameter estimation and model 
selection. Bull. Natl. Res. Inst. Far. Seas. Fish., 29: 57-114. (In Japanese, with English abstract.)

Huner, J., H. Dupree and D. Greenland. 1984. Harvesting, grading, and holding fish. In: Third Report to Fish Farmers. US Fish and Wildlife Service, Washington, DC, pp. 158-164.

Karplus I., V. Alchanatis and B. Zion. 2005. Guidance of groups of guppies (Poecilia reticulata) to allow sorting by computer vision. Aquacultural Engineering 32: 509-520.

Liang Y.T. and Y.C. Chiou. 2009. Machine vision based automatic raw fish handling and weighing system, In: Chien B., T. Hong, S. Chen and M. Ali (eds.). Next-generation Applied Intelligence 22nd International conference on Industrial, Engineering and other applications of applied intelligent systems, IEA/AIE 2009 Tainan, Taiwan, June 2009, Proceedings.

Millar, R.B. 1992. Estimating the size-selectivity of fishing gear by conditioning on the total catch. J. Am. Stat. Assoc. 87, 962-968.

Millar R. B. and R. J. Fryer. 1999. Estimating of size-selectivity curves of towed gear, traps, nets and hook. Rev. Fish Biol. Fish., 9: 89116.

Nelder, J.A. and, R. Mead. 1983. A simplex method for function minimization. Comput. J., 7: 308-313.

Revill A. and R. Holst. 2004. The selective properties of some sieve nets. Fisheries Research 66: 171-183.

Sardà F., N. Bahamon, B. Molí and F. Sardà-Palomera. 2006. The use of a square mesh codend and sorting grids to reduce catches of young fish and improve sustainability in a multispecies bottom trawl fishery in the Mediterranean. Scientia Marina 70 (3): 347-353.

Tokai T. 1997. Maximum likelihood parameter estimates of a mesh selectivity logistic model through SOLVER on MS -Excel. Bull. Jpn. Fish. Ocean. 61, 288-298.

Trimpey, J., C. Engle, D. Heikes, K.B. Davis, A. Goodwin. 2004. A comparison of new in-pond grading technology to live-car grading for food-sized channel catfish Ictalurus punctatus. Aquacultural Engineering 31, 263-276.

Xu, X. and R.B. Millar. 1993. Estimation of trap selectivity for male snow crab (Chionoecetes opilio). using the SELECT modeling 
approach with unequal sampling effort. Can. J. Fish. Aquat. Sci. $50,2485-2490$.

\section{الملخص العربى}

\section{هندسة عملية التدريج داخل أحواض السمك البلطي \\ و و ائل محمد المسيري \\ *عيد الثحات عبدالله}

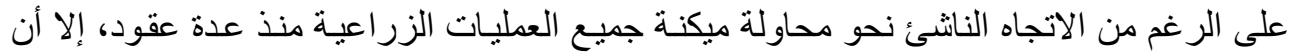

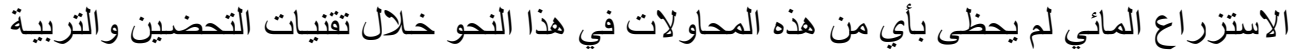

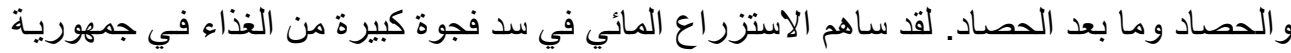

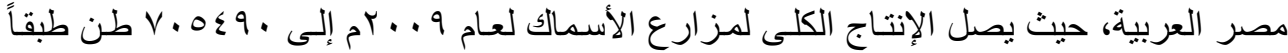

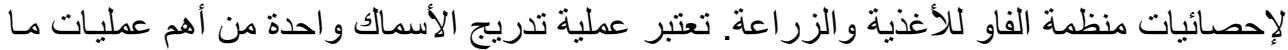

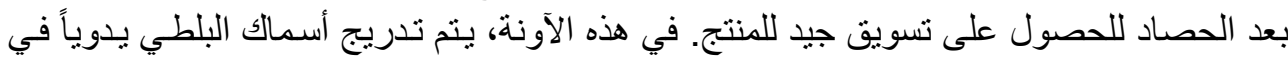

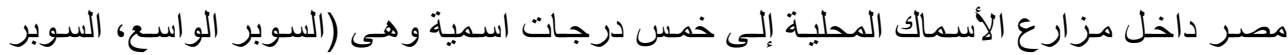

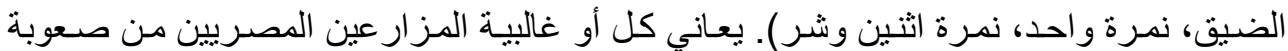

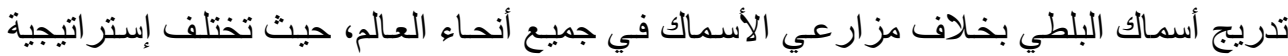

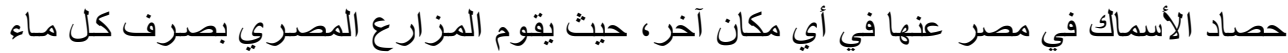

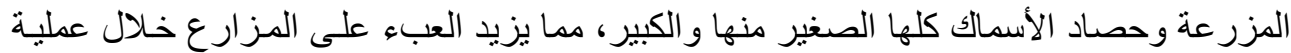

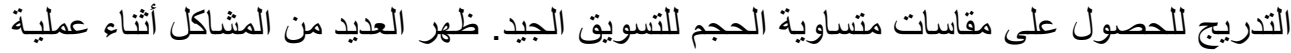

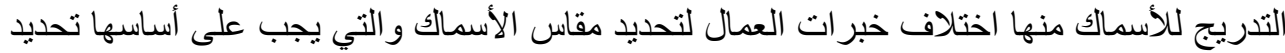

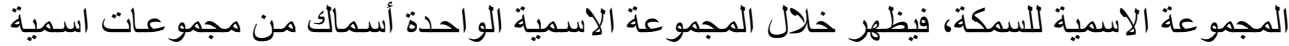
أخرى، مما يؤثر بالسلب على جودة التدريج وكذا التسويق. فضلاً عن ذللك، ارتفاع الجاء أجر العمال

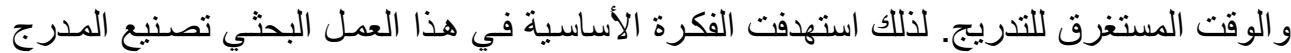

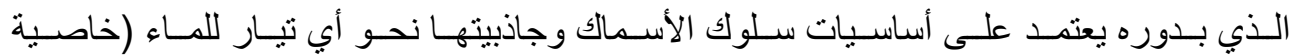

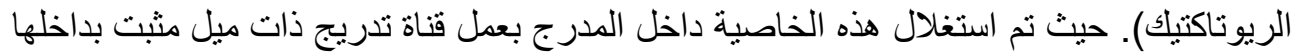

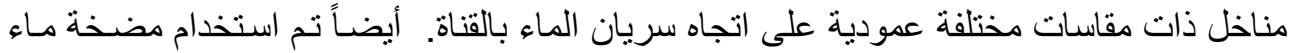

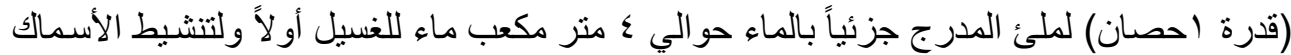

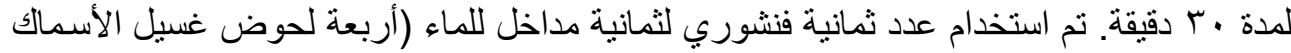

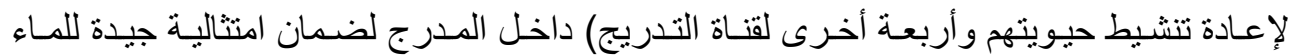

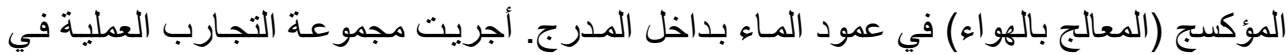

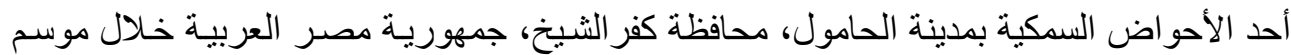

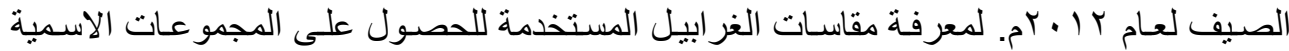

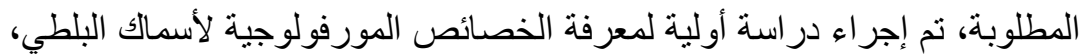

\section{* * أستاذ مساعد ـ قسم الهندسة الزراعية، كلية الزراعة، جامعة كفر الثيخ، مصر.

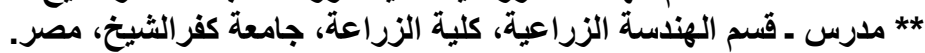


حيث تم در اسة العلاقة بين طول و عمق وسمك السمكة ووزن كل منها. كانت مقاسات الغر ابيل التي تم التوصل إليها نهائياً لتصنيع مدرج طول الأسماك كالآتي:

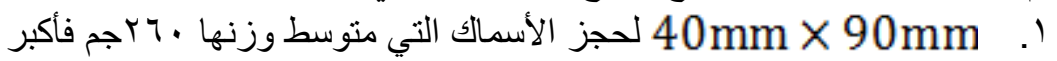

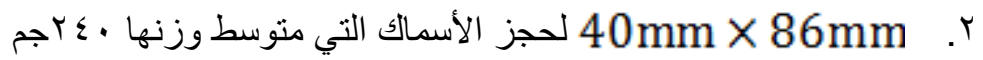

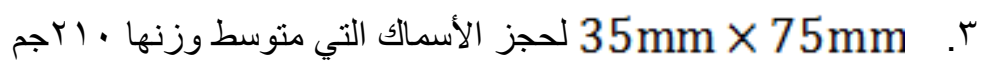

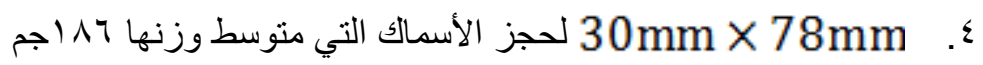

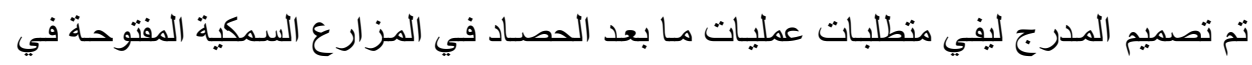

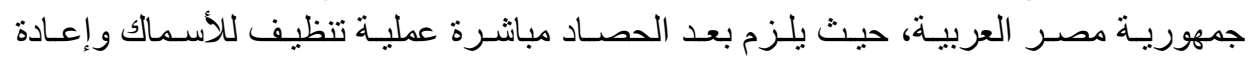

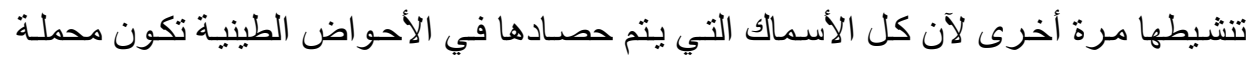

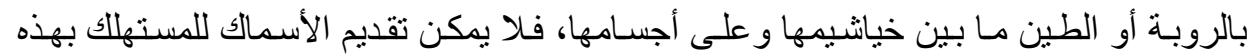

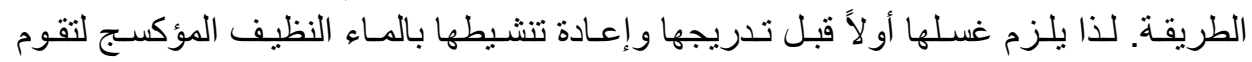

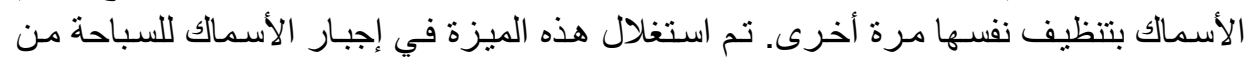

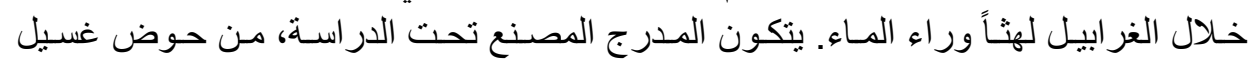
1.5 X 2.2

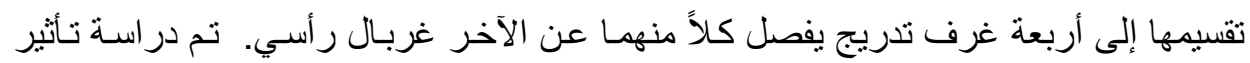

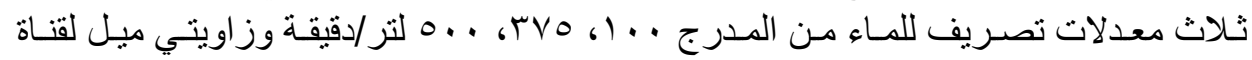

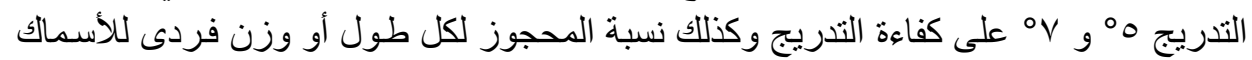

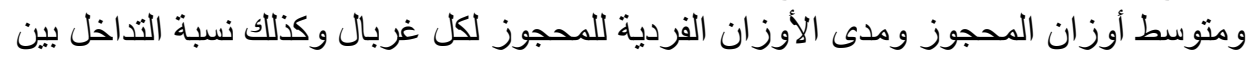

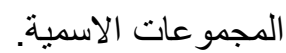
بعد إجر اء مجموعة التجارب العملية والانتهاء من الدراسة، تم التوصل إلى أن متوسط أوزان الأسماك المحجوزة خلف كلف كل غربال كانت كالآتي:

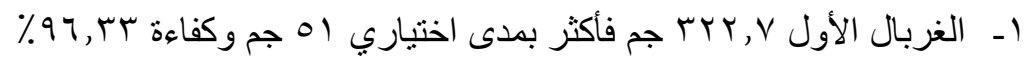

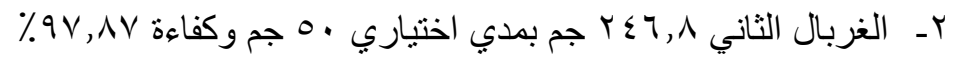

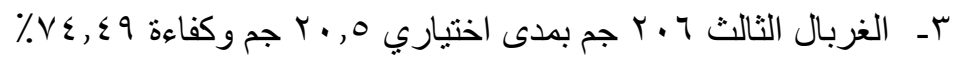

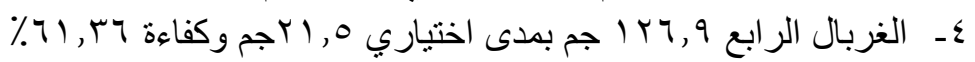

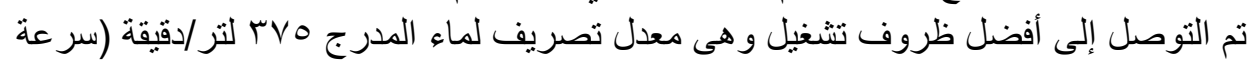

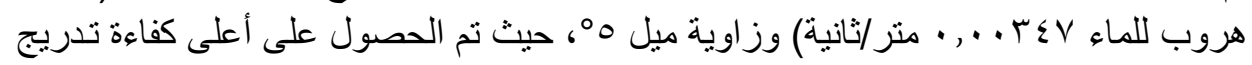

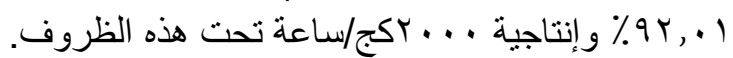

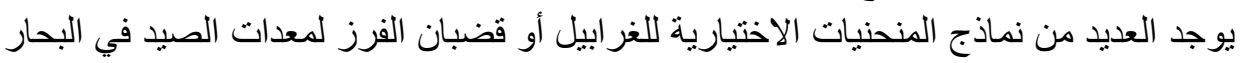

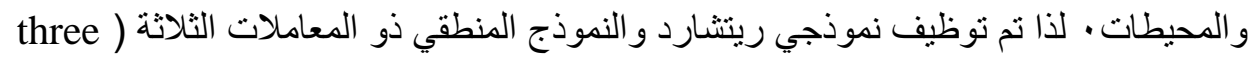
(parameters-logistic

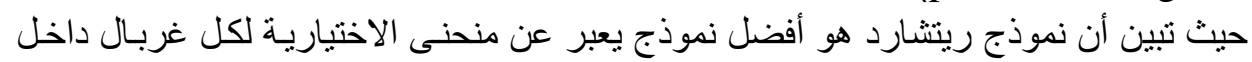
المدرج تحت الدر اسة. ندون. 